\title{
Use of Plastic Packages for Food and Liquids in a prospective cohort of pregnant patients - Association analyses with birthweight and pregnancy duration
}

Patrick Stelzl ( $\sim$ patrick.stelzl@kepleruniklinikum.at)

Johannes Kepler Universitat Linz https://orcid.org/0000-0002-5915-7788

Constanza Pontones

Johannes Kepler Universitat Linz

Paul Gass

Johannes Kepler Universitat Linz https://orcid.org/0000-0002-4239-5528

Julius Emons

Johannes Kepler Universitat Linz

Judith Schwitulla

Johannes Kepler Universitat Linz

Michael O. Schneider

Johannes Kepler Universitat Linz https://orcid.org/0000-0002-7583-307X

\section{Eva Schwenke}

Johannes Kepler Universitat Linz

Lothar Haeberle

Johannes Kepler Universitat Linz

Matthias Ruebner

Johannes Kepler Universitat Linz

Florian Faschingbauer

Johannes Kepler Universitat Linz

Matthias W. Beckmann

Johannes Kepler Universitat Linz

Adriana Titzmann

Johannes Kepler Universitat Linz

\section{Research Article}

Keywords: Endocrine Disrupting Chemicals, EDCs, Plastic Packages, Preterm Birth, Birthweight, Pregnancy Duration 
Posted Date: May 27th, 2021

DOl: https://doi.org/10.21203/rs.3.rs-218855/v1

License: (c) (i) This work is licensed under a Creative Commons Attribution 4.0 International License. Read Full License 


\section{Abstract}

Purpose: Exposure to endocrine disrupting chemicals (EDCs) is ubiquitous in modern civilization and their impact on hormonal regulation in vivid organisms is well established. These substances also seem to play a pivotal role during pregnancy as they might influence birth and pregnancy outcomes, such as fetal birthweight and pregnancy duration.

The objective of this study is to investigate the associations of increased EDC exposure during pregnancy with changes of fetal birthweight and pregnancy duration.

Methods: Individual use of plastic food and liquid packages was evaluated in 493 pregnant patients from the Clinical Gravidity Association Trial and Evaluation (CGATE) cohort using a three item lifestyle questionnaire concerning plastic consumption habits. To assess exposure to EDCs patients were further grouped into risk categories, and the associations with birthweight and pregnancy duration were investigated using a linear regression model.

Results: For none of the investigated plastic consumption habits concerning drinking water, food from cans/plastic or beverage cartons (Tetra Pak) a statistically significant association with birthweight could be found. Moreover, no significant correlation between plastic consumption in regards of drinking water and food from cans/plastic with pregnancy duration could be detected. Interestingly, a statistically significant pregnancy prolongation of 0.4 weeks $(p=0.01,95 \% \mathrm{Cl}: 0.1 ; 0.7)$ was observed with increasing consumption of Tetra Pak.

Conclusion: The impact of plastic package consumption during pregnancy does not seem to have a major effect on birthweight or pregnancy duration, however the direction in which the statistically nonsignificant differences were seen were into the expected direction. Therefore larger studies are warranted to investigate this potentially important epidemiological factor.

\section{Introduction}

According to the World Health Organization (WHO), a total of about 800 exogenous substances or mixtures - referred as endocrine disrupting chemicals (EDCs) - are known (1). For example, phthalates are found as plasticizers in various plastic packaging materials and are not chemically bound to plastics or other products. Consequently, these substances can easily detach themselves and hence migrate into food or even water and enter human organisms via daily food and fluid intake (2). During pregnancy EDCs are able to pass over to the fetus through the placental barrier and postpartum via breast milk directly to the child (3).

EDCs are capable of interfering with the hormone system of living organisms. However, the exact pathophysiological mechanisms of these substances are still unknown (1).

EDCs are able to interact with estrogen- and/or androgen receptors, thus leading to disruption or modulation of normal estrogen- and/or androgen-ligand-activity $(4,5)$. Moreover, they are known to 
increase intracellular peroxisome proliferator-activated receptors, and thereby cause deactivation of $17 \beta$ hydroxysteroid-dehydrogenase (converting enzyme of androstenedione into testosterone and estrone into estradiol). This cascade is known to be associated with preterm birth (PTB) (6-8).

Fetal birthweight might also be affected through hormonal imbalance caused by the interaction of EDCs with estrogen receptors or through alteration of lipid levels $(9,10)$.

Pregnancy duration was also observed to be impacted by various hormonal effects of EDCs, such as bisphenol A (BPA). As "synthetic hormone" BPA is able to bind to estrogen receptors leading to estrogenmediated gene expression (11). Moreover, this substance class was found to alter the signal cascade of thyroid synthesis and to have an affinity to glucocorticoid receptors (12). Thus, the inflammatory potential of BPA, which is reflected by increase of C-reactive-protein might be responsible for reduction of pregnancy duration (13).

Summarizing current evidence regarding EDC exposure of pregnant patients and their offspring and the potential impact on pregnancy and birth outcomes, such as birthweight and pregnancy duration, a heterogeneous data situation is obvious. The objective of this work was to further investigate the associations between increased exposure to EDCs during pregnancy and primary outcome parameters changes in birthweight and pregnancy duration. As modern plastic packaging materials for foods and drinks contain considerable amounts of EDCs, individual plastic consumption was assessed with a pregnancy diary including dietary patterns of patients from the Franconian "Clinical Gravidity Association Trial and Evaluation (CGATE)" cohort and further correlated with birthweight in 490 and pregnancy duration in 493 patients.

\section{Methods}

Within the scope of the CGATE program - a prospective observational study in pregnant patients from March 2010 until December 2014 - a total of 688 individuals were recruited with the aim of identifying novel biomarkers to predict unfavorable events during pregnancy and adverse birth outcomes. Inclusion criteria were patients with sonographically viable and intrauterine singleton gravidity before $14+0$ weeks of gestation, patient age of at least 18 years and willingness to complete a pregnancy diary, a structured questionnaire concerning lifestyle, body weight, nutrition and pregnancy-related disorders, such as restless leg syndrome and depression, which had to be completed every month until the end of pregnancy. Moreover biomarkers $(14,15)$, blood and urine samples were collected during study inclusion, optional visits between $20-23$ weeks' gestation and at delivery. Exclusion criteria were patients with multiple pregnancies, patients experiencing miscarriage/fetal demise or being diagnosed with fetal anomalies, individuals with missing consent-forms and/or insufficient pregnancy diary documentation. Moreover, the maternity record (Mutterpass) - a mandatory document for obstetricians to monitor pregnancy in Germany - and the patient's chart at birth were obtained for documentation of mother-, child- and pregnancy-characteristics. Patients were followed up until 6 months postpartum. A total of 493 
individuals met the study criteria. From all of those pregnancy duration and from 490 subjects birthweight values were available and further included into statistical analyses.

Individual plastic consumption was evaluated using a three item lifestyle questionnaire (see Table 1) within the pregnancy diary. Patients were asked to complete the diary/questions at study begin (first trimester), 16, 20, 24, 28, 32, 36 and 38-40 weeks of gestation.

Plastic consumption during pregnancy was categorized into "Drinking Water from Plastic Packaging", "Food from Plastic Packaging and Cans" and "Drinks from Beverage Cartons (Tetra Pak)". In order to be able to statistically present and investigate the following described answer possibilities of the three questions concerning exposition to EDCs, these were grouped into consumption habits and following exposure risk categories: 0 (low risk), 1 (moderate risk) and 2 (high risk) (see Table 1).

To assess the patient's habits concerning drinking water consumption answer possibilities of question 1 "From which source do you directly consume drinking water?" were categorized as following: Answers a) "Mostly glass bottles" and b) "Mostly tap water" as category 0: "No plastic use"; answer c) "Don't know exactly (mixed)" as category 1: "Moderate plastic use"; answers d) "Mostly reuseable plastic bottles", e) "Mostly disposable plastic bottles" and f) "I don't drink water, only other drinks" as category 2 :

"Predominantly plastic use" (see Table 1).

Table 1 Three item lifestyle questionnaire within the pregnancy diary of the CGATE-cohort patients

Individual Plastic Consumption

"Drinking Water from Plastic Packaging"

Q1 From which source do you directly consume drinking water?
a) Mostly glass bottles
b) Mostly tap water
c) Don't know exactly (mixed)
d) Mostly reusable plastic bottles
e) Mostly disposable plastic bottles
f) I don't drink water, only other drinks
No plastic use
No plastic use
Moderate plastic use

0
Predominantly plastic use
Predominantly plastic use
Predominantly plastic use

1

Consumption Habit Category

"Food from Plastic Packaging and Cans"

Q2 How often do you consume food or ready meals from cans or plastic packaging?
a) Never
b) 1-2 times per month
c) 1-2 times per week
d) Almost daily/daily

(almost) never

(almost) never

$1-2 /$ week

(almost) daily

"Drinks from Beverage Cartons (Tetra Pak)?"

Q3 How often do you consume drinks (including milk) from beverage cartons (Tetra Pak)?
a) Never
(almost) never
0
b) 1-2 times per month
(almost) never
0
c) 1-2 times per week
$1-2 /$ week
d) Almost daily/daily
(almost) daily

Answer possibilities categorized into consumption habits and exposure risk categories 0: low risk, 1: moderate risk and 2: high risk 
For evaluation of food consumption from plastic packaging and cans answer possibilities of question 2 "How often do you consume food or ready meals from cans or plastic packaging?" were categorized as following: Answers a) "Never" and b) "1-2 times per month" as category 0: "(almost) never"; answer c) "12 times per week" as category 1: "1-2/week"; answer d) "Almost daily/daily" as category 2: "(almost) daily" (see Table 1).

Question 3 "How often do you consume drinks (including milk) from beverage cartons (Tetra Pak)?" was answered and categorized in analogy to question 2 (see Table 1).

Mean values of categorized answer possibilities - ranging from 0 to 2 - were only calculated if the questionnaire on nutrition and lifestyle was completed at least at three time points during pregnancy period.

Birthweight was measured after parturition in the delivery room by the attending midwife with a standard baby scale and was subsequently entered into the birth documentation system ViewPoint 5 (৫ 1995-2020 General Electric Company, GE Healthcare). Birthweights of patients delivering at another hospital were obtained from the maternity record. From a total of 490 patients birthweight was documented. Pregnancy Duration was also documented in analogy or rather taken from the maternity record. Gestational age was calculated from the first day of the patient's last menstrual period or corrected after fetal crown-rumplength in the first trimester, when gestational age determined by sonographic measurement was deviating more than a week. This variable was documented in all 493 individuals.

For the representation of the patient collective descriptive statistics were conducted, and the absolute use of plastic packaging during pregnancy was analyzed. Additionally, birthweight was descriptively compared with average plastic consumption per patient during pregnancy.

The associations between increased plastic consumption with changes in birthweight and pregnancy duration were analyzed using a linear regression model. The following predictors were included: child's sex, mother's BMl, father's BMl, parity ( $>0$ versus 0 ) and previous miscarriages ( $>0$ versus 0 ). Plastic consumption was integrated as a continuous variable - ranging from 0 to 2 (definition see above and Table 1) - into the linear model.

The significance level was set to $a=0.05$. Statistical analyses were performed using the software $R$ (Version 3.4.0, R Core Team, Vienna, Austria, 2017).

\section{Results}

A total of 490 patients were included into statistical analyses for birthweight and 493 individuals for pregnancy duration. An overview of the variables observed and the patient characteristics are shown in Table 2.

Table 2 Characteristics of study popluation 


\begin{tabular}{lcc}
\hline Birthweight (in kg) & $3339.6(890.0-5130.0)$ & 519.9 \\
Pregnancy Duration (in weeks) & $39.7(27.0-43.0)$ & 1.8 \\
BMI mother (in $\left.\mathrm{kg} / \mathrm{m}^{2}\right)$ & $23.5(16.2-46.0)$ & 4.5 \\
BMI father (in kg/m $\left.\mathrm{m}^{2}\right)$ & $25.9(17.2-38.9)$ & 3.3 \\
\hline & $\mathbf{n}$ & $\%$
\end{tabular}

Para

0

$242 \quad 49.3$

$>0$

$249 \quad 50.7$

Fetal Sex

Male

$241 \quad 49.2$

Female

$249 \quad 50.8$

Miscarriage

0

$361 \quad 73.5$

$>0$

$130 \quad 26.5$

$n=$ Number,$S D=$ Standard Deviation

"Predominantly plastic use" in concerns of drinking water was much more common than "Moderate or no plastic use" (see Table 3 and Figure 1A). The majority of patients "(almost) never" consumed food from plastic packaging and cans (see Table 3 and Figure 1B). Controversially, "(almost) daily" use of Tetra Pak could be observed more frequently within the study population (see Table 3 and Figure 1C). Interestingly, the consumption habits regarding all 3 plastic packaging modalities remained almost stable over all time points of pregnancy.

Table 3 Percentages of consumption habits regarding plastic packaging modalities for

\begin{tabular}{|c|c|c|c|c|c|c|c|c|}
\hline Exposure Risk Category & Trim 1 & 16 weelss & 20 weelss & 24 weelss & 28 weelss & 32 weelss & 36 weelss & 40 weelss \\
\hline Diniting Tater flan Plcatic Paxkgging & 370 patients & 475 patients & 482 patients & 481 patients & 483 patients & 467 patients & 376 patients & 420 patients \\
\hline Noplastic use & $28.4 \%$ & $30.3 \%$ & $30.7 \%$ & $31.2 \%$ & $31.3 \%$ & $328 \%$ & $34.3 \%$ & $30.5 \%$ \\
\hline Moderate plastic use & $13.0 \%$ & $15.4 \%$ & $14.9 \%$ & $13.9 \%$ & $13.4 \%$ & $135 \%$ & $141 \%$ & $136 \%$ \\
\hline Predominantly plastic use & $58.6 \%$ & $54.3 \%$ & $54.4 \%$ & $549 \%$ & $55.3 \%$ & $537 \%$ & $516 \%$ & $55.9 \%$ \\
\hline Foodffon Plastic Paxigging and Car & 371 patients & 476 patients & 482 patients & 482 patients & 485 patients & 468 patients & 377 patients & 423 patients \\
\hline (amosi) never & $70.3 \%$ & $668 \%$ & $65.4 \%$ & $63.7 \%$ & $63.3 \%$ & $622 \%$ & $59.9 \%$ & $65.7 \%$ \\
\hline $1-2 x$ wesk: & $23.2 \%$ & $23.7 \%$ & $23.4 \%$ & $24.3 \%$ & $25.2 \%$ & $259 \%$ & $260 \%$ & $260 \%$ \\
\hline (almost) daily & $6.5 \%$ & $9.5 \%$ & $11.2 \%$ & $120 \%$ & $11.5 \%$ & $119 \%$ & $141 \%$ & $8.3 \%$ \\
\hline Dins flom Beverage Cator (Tet cpxik) & 373 patients & 476 patients & 483 patients & 484 patients & 485 patients & 468 patients & 375 patients & 424 patients \\
\hline (almost) never & $126 \%$ & $120 \%$ & $10.2 \%$ & $13.0 \%$ & $11.3 \%$ & $105 \%$ & $9.6 \%$ & $13.4 \%$ \\
\hline $1-2 x /$ weat: & $23.9 \%$ & $20.2 \%$ & $18.4 \%$ & $14.1 \%$ & $14.5 \%$ & $141 \%$ & $147 \%$ & $20.3 \%$ \\
\hline (almost) daily & $63.5 \%$ & $67.8 \%$ & $71.4 \%$ & $729 \%$ & $74.2 \%$ & $754 \%$ & $75.7 \%$ & $66.3 \%$ \\
\hline
\end{tabular}

Within the study cohort, neither high consumption of drinking water from plastic bottles $(-17.8 \mathrm{~g}, \mathrm{p}=0.48$, $95 \% \mathrm{Cl}:-66.9 ; 31.3)$, nor foods from cans or plastic packaging $(-40.9, \mathrm{p}=0.23,95 \% \mathrm{Cl}$ : $-107.5 ; 25.7)$, nor drinks from Tetra Pak (-17.5 g, $\mathrm{p}=0.63,95 \% \mathrm{Cl}$ : -88.3 ; 53.3) revealed a statistical significant association with change of birthweight (see Table 4). 
Table 4 Associations of high plastic consumption habits concering all packaging modalities and change of birthweight

\begin{tabular}{|c|c|c|}
\hline Variable & Estimate $(95 \% \mathrm{Cl})$ & p-value \\
\hline Drinking water (in g) & $-17.8(-66.9 ; 31.3)$ & 0.48 \\
\hline Fetal sex (female) & $-186.9(-264.4 ;-109.3)$ & $<0.001$ \\
\hline BMI mother & $6.7(-2.0 ; 15.5)$ & 0.13 \\
\hline BMI father & $7.7(-4.5 ; 20.0)$ & 0.22 \\
\hline Parity $\geq 1$ & $102.4(-24 ; 180.7)$ & 0.01 \\
\hline Miscarriage $\geq 1$ & $-41.9(-129.1 ; 45.3)$ & 0.35 \\
\hline Pregnancy Duration & $164.2(142.3 ; 186.0)$ & $<0.001$ \\
\hline Cans/Plastic (in g) & $-40.9(-107.5 ; 25.7)$ & 0.23 \\
\hline Fetal sex (female) & $-185.4(-263.0 ;-107.9)$ & $<0.001$ \\
\hline BMI mother & $7(-1.8 ; 15.7)$ & 0.12 \\
\hline BMI father & $6.7(-5.4 ; 18.8)$ & 0.28 \\
\hline Parity $\geq 1$ & 107 (28.9; 185.1) & 0.01 \\
\hline Miscarriage $\geq 1$ & $-41.9(-129.0 ; 45.3)$ & 0.35 \\
\hline Pregnancy Duration & $165(143.2 ; 186.9)$ & $<0.001$ \\
\hline Tetra Pak (in g) & $-17.5(-88.3 ; 53.3)$ & 0.63 \\
\hline Fetal sex (female) & $-186.7(-264.3 ;-109.1)$ & $<0.001$ \\
\hline BMI mother & $6.7(-2.1 ; 15.4)$ & 0.14 \\
\hline BMI father & $7.3(-4.9 ; 19.5)$ & 0.24 \\
\hline Parity $>1$ & $105.7(27.5 ; 183.9)$ & 0.01 \\
\hline Miscarriage $\geq 1$ & $-42.1(-129.3 ; 45.2)$ & 0.34 \\
\hline Pregnancy Duration & $165.3(143.3 ; 187.3)$ & $<0.001$ \\
\hline Overall plastic consumption (in g) & $-66.9(-166.6 ; 32.9)$ & 0.19 \\
\hline Fetal sex (female) & $-185.9(-263.3 ;-108.4)$ & $<0.001$ \\
\hline BMI mother & $6.5(-2.3 ; 15.2)$ & 0.15 \\
\hline BMI father & $8.0(-4.2 ; 20.2)$ & 0.20 \\
\hline Parity $\geq 1$ & $104.2(26.2 ; 182.1)$ & 0.01 \\
\hline Miscarriage $\geq 1$ & $-42.6(-129.8 ; 44.5)$ & 0.34 \\
\hline Pregnancy Duration & $165.2(143.3 ; 187)$ & $<0.001$ \\
\hline
\end{tabular}

Moreover, an overall plastic consumption analysis including all three examined packaging modalities drinking water, cans and plastic food packaging as well as Tetra Pak - could not display a statistically significant association between increasing plastic consumption and birthweight $(-66.9 \mathrm{~g}, \mathrm{p}=0.19,95 \% \mathrm{Cl}$ : -166.6; 32.9) (see Table 4).

Among all analyses, confounding factors child's sex (female), parity and pregnancy duration were the only variables reflecting statistically significant changes of birthweight (see Table 4). 
In analogy, neither the correlation analyses of drinking water consumption from plastic packaging $(-0.1$ weeks, $p=0.27,95 \% \mathrm{Cl}:-0.3 ; 0.1)$, nor food from cans or plastic packaging $(0.1$ weeks, $p=0.51,95 \% \mathrm{Cl}$ : $-0.2 ; 0.4)$, nor overall plastic consumption ( 0.2 weeks, $p=0.42,95 \% \mathrm{Cl}:-0.3 ; 0.6)$ showed a statistical significant change of pregnancy duration (see Table 5).

Table 5 Associations of high plastic consumption habits concering all packaging modalities and change of pregnancy duration

\begin{tabular}{lrr} 
Variable & Estimate $(95 \%-\mathrm{Cl})$ & p-value \\
\hline Drinking water (in weeks) & $-0.1(-0.3 ; 0.1)$ & 0.27 \\
Fetal sex (female) & $0.2(-0.1 ; 0.6)$ & 0.23 \\
BMI mother & $0(-0.1 ; 0.0)$ & 0.51 \\
BMI father & $0(0.0 ; 0.1)$ & 0.13 \\
Parity $\geq 1$ & $-0.2(-0.6 ; 0.1)$ & 0.24 \\
Miscarriage $\geq 1$ & $-0.4(-0.8 ;-0.1)$ & 0.03 \\
\hline Cans/Plastic (in weeks) & $0.1(-0.2 ; 0.4)$ & 0.51 \\
Fetal sex (female) & $0.2(-0.1 ; 0.5)$ & 0.24 \\
BMI mother & $0(-0.1 ; 0.0)$ & 0.53 \\
BMI father & $0(0.0 ; 0.1)$ & 0.17 \\
Parity $\geq 1$ & $-0.2(-0.5 ; 0.1)$ & 0.26 \\
Miscarriage $\geq 1$ & $-0.4(-0.8 ;-0.1)$ & 0.03 \\
\hline Tetra Pak (in weeks) & $0.4(0.1 ; 0.7)$ & 0.01 \\
Fetal sex (female) & $0.2(-0.1 ; 0.5)$ & 0.24 \\
BMI mother & $0(0.0 ; 0.0)$ & 0.72 \\
BMI father & $0(0.0 ; 0.1)$ & 0.26 \\
Parity $\geq 1$ & $-0.2(-0.6 ; 0.1)$ & 0.23 \\
Miscarriage $\geq 1$ & $-0.4(-0.8 ; 0.0)$ & 0.03 \\
\hline Overall plastic consumption (in weeks) & $0.2(-0.3 ; 0.6)$ & 0.42 \\
Fetal sex (female) & $0.2(-0.1 ; 0.5)$ & 0.23 \\
BMI mother & $0(0.0 ; 0.0)$ & 0.58 \\
BMI father & $0(0.0 ; 0.1)$ & 0.21 \\
Parity $\geq 1$ & $-0.2(-0.5 ; 0.2)$ & 0.28 \\
Miscarriage $\geq 1$ & $-0.4(-0.8 ; 0.0)$ & 0.03 \\
\hline
\end{tabular}

Interestingly, a statistically significant pregnancy prolongation of 0.4 weeks $(p=0.01,95 \% \mathrm{Cl}: 0.1 ; 0.7)$ was observed for patients consuming drinks from Tetra Pak with a high frequency (see Table 5).

Moreover, confounding variable previous miscarriages $(\geq 1)$ was statistically significant associated with decreasing pregnancy duration (see Table 5). 


\section{Discussion}

This work investigated patient's consumption habits in regards of food and beverages from plastic packaging within the CGATE cohort, aiming on the specification of EDC exposure during pregnancy and the associations with changes of fetal birthweight and pregnancy duration.

BPA and phthalates are known for causing epigenetic modifications of fetuses and germ cells and thus might lead to negative fetal programming $(16,17)$. Moreover, phthalates affect thyroid metabolism and influence urine thyroxine levels. Johns et al. found an inverse correlation between 11 measurable phthalate metabolites in urine and the concentrations of fT3 and fT4, which was increasing with duration of pregnancy (2). Hypothyroidism might lead to mental retardation with potentially severe disability and spasticity of the child, but might also result in an increase of birthweight $(18,19)$.

The EARTH study including 346 patients examined pre-conceptual and prenatal urine samples in concerns of their bisphenol $\mathrm{A}$ and $\mathrm{S}$ concentration and observed an inverse relationship between bisphenol concentration and birthweight; high bisphenol levels in pre-conceptual urine were associated with an average weight reduction of $119 \mathrm{~g}(95 \% \mathrm{Cl}$ : -212; -27) and increased bisphenol concentrations in prenatal urine revealed a decrease of $75 \mathrm{~g}(95 \% \mathrm{Cl}:-153 ; 2)(20)$.

Within the ALSPAC study 447 mother-daughter dyads were investigated. Elevated maternal serum concentrations of perfluorooctanoate and perfluorohexane sulfonate were correlated with $133 \mathrm{~g} \mathrm{(95 \%} \mathrm{Cl:}$ $-237 ; 30)$ or $108 \mathrm{~g}(95 \% \mathrm{Cl}:-206 ; 10)$ lower birthweights of girls $(10)$.

Controversially, a study from Spain analyzing data of 488 mother-child pairs from the INMA-Sabadell birth cohort found that with increasing urine concentrations of mono-benzyl phthalate femur length was increasing by $3.7 \%(95 \% \mathrm{Cl}: 0.75 ; 6.63)$ within 20 to 34 weeks of gestation. Additionally, birthweight among boys was $48 \mathrm{~g}(95 \% \mathrm{Cl}: 6$; 90$)$ higher. Interestingly an inverse correlation with birthweight of girls $(-27 \mathrm{~g}, 95 \% \mathrm{Cl}:-79 ; 25$, interaction $\mathrm{p}=0.04)$ was observed (5). However, our results didn't reveal a statistical significant change of birthweights among individuals with increasing plastic consumption habits during pregnancy.

Further statistical analyses of CGATE data regarding the correlation of increasing food and beverage consumption from plastic packaging or cans with pregnancy duration did not show a significant association, besides Tetra Pak with a statistically significant pregnancy prolongation, highlighting that pregnancy duration might though had been affected by exposure to EDCs.

In German supermarkets, many dairy products, fruit juices and even drinking water are retailed in paperboard boxes referred as Tetra Pak. The inner layer of these beverage cartons is laminated with a thin plastic film (21). A Chinese study by Huang et al. including 207 patients analyzed the concentrations of 15 different phthalates in the cord blood after delivery and found, that an exposure to phthalates (except to dicyclohexyl phthalate) was statistically significant associated with a decrease of pregnancy duration and with PTB (6). Padmanabhan et al. investigated 40 patients in Michigan and found no 
association between maternal EDC levels and pregnancy duration (11), which is in accordance with a study from Wolff et al. including a cohort of 367 patients from New York City (22). Within a collective of 60 individuals from Mexico City, Cantonwine et al. found, that elevated BPA urine concentrations during pregnancy had an odds ratio of $2.5(95 \% \mathrm{Cl}: 1.1 ; 6.0)$ for occurrence of PTB before 37 weeks of gestation (23). Another study by Cantonwine et al. investigated 130 PTB cases and 352 term controls in Birmingham and Boston. Mother's urine was tested for BPA concentration at four time points during pregnancy and had no significant association with PTB $(\mathrm{OR}=1.21,95 \% \mathrm{Cl}: 0.79 ; 1.85)$. However, stratified analyses of sexes revealed a significant correlation of BPA with PTB in girls (OR $=1.8, p$-value $=0.04,95 \%$ Cl: $1.02,3.13)(12)$.

Controversially, a study from 2009 by Adibi et al. examining 300 patients in the United States found an association between phthalate concentration and longer duration of pregnancy. They observed a pregnancy prolongation by 1.1 to 1.3 days. This association was even stronger, when comparing the concentrations of phthalate metabolites in individuals at the $75^{\text {th }}$ percentile and the $25^{\text {th }}$ percentile $(2.3$ days, $\mathrm{Cl}: 1.4$; 3.3) (24).

Based on the CGATE data it can be stated, that there was no median "excessive" consumption of food from cans and plastic packaging, which becomes evident after statistical analysis of question 2 in the pregnancy diary, where option "(almost) never" was chosen most often. Thus, the overall exposure of our patient collective to EDCs might rather have been intermediate to low. Accordingly, change of fetal birthweight was not statistically significant within this study population.

Two Italian research groups investigated bisphenol concentrations of most popular beverages packed in cans, plastic containers, glass bottles and Tetra Pak in Campania province (Italy) and detected, that $100 \%$ of milk products contained BPA, whereas BPA was only found in $57 \%$ of carbonated and $50 \%$ of noncarbonated drinks. Interestingly, dairy products showed the highest BPA levels, which might be explained by precipitation of bisphenols through presence of milk lipids. Within the groups of carbonated and noncarbonated beverages cans showed highest BPA concentrations, followed by plastic packaging and Tetra Pak. Liquids from glass bottles were never contaminated with bisphenols (25-27). Consequently, beverages packed in Tetra Pak seem to have lowest EDC concentrations among all frequently used plastic packaging materials. This might be an explanation for observed pregnancy prolongation within the group of frequent Tetra Pak use in CGATE, as this subgroup regularly consumed liquids from a more "harmless" packaging source.

Limitations of this study are missing analyses of maternal urine/serum or fetal cord blood and shortage of the patient questionnaire to exactly determine EDC exposure. Strengths are the prospective cohort design, the high number of participating individuals, simplicity of the patient questionnaire, and especially the "freedom" to keep a pregnancy diary to avoid unnecessary and stressful study visits.

\section{Conclusion}


Although majority of evidence reflects, that increased exposure to EDCs, such as BPA or phthalates, is more likely to reduce birthweight and duration of pregnancy, results of many studies are conflicting. Regarding these phenotypes the results of our study are in accordance with this heterogeneous data situation. Further investigations are warranted to especially better evaluate the influence of increased EDC exposure on birth and pregnancy outcomes.

\section{Declarations}

\section{Funding}

This study was departmentally funded by the Women's Center Erlangen.

\section{Conflicts of interest}

The authors declare that they have no conflicts of interest.

\section{Consent to participate}

Informed consent was obtained from all individual participants included in the study.

Consent for publication

Not applicable

\section{Ethics approval}

The study was approved by the Ethics Committee of the medical faculty at Friedrich Alexander University of Erlangen-Nuremberg, Erlangen, Germany.

Availability of data and material

The datasets used and/or analysed during the current study are available from the corresponding author on reasonable request.

Code availability.

Not applicable

\section{Acknowledgments}

The contribution of Adriana Titzmann to this publication was performed in partial fulfillment of the requirements for obtaining the doctoral degree "Dr. med.". Parts of the work published here have been used for her doctoral thesis at the Medical Faculty of the Friedrich-Alexander University ErlangenNuremberg (FAU).

\section{Authors' contributions}


PS is the first and corresponding author and was a major contributor in writing the manuscript and interpreting the analyzed data concerning plastic consumption habits of the CGATE cohort.

$\mathrm{CP}$ was an essential contributor in editing and critically reviewing the manuscript.

PG, JE, MS, ES, FF were minor contributors in writing the manuscript and essential contributors in editing and critically reviewing the manuscript.

JS and LH were major contributors for statistical analyses of used CGATE cohort data.

MR is responsible for the CGATE biorepository and was a minor contributor in writing the manuscript and essential contributor in editing and critically reviewing the manuscript.

MWB is the head of the Women's Center Erlangen and in charge of the departmental funding for this study. He was a minor contributor in writing the manuscript and an essential contributor in editing and critically reviewing the manuscript.

AT is the last author and was a major contributor in writing the manuscript and interpreting the analyzed data concerning plastic consumption habits of the CGATE cohort.

All authors read and approved the final manuscript.

\section{Compliance with Ethical Standards}

\section{Conflict of interest}

PS declares that he has no conflict of interest.

$\mathrm{CP}$ declares that she has no conflict of interest.

PG declares that he has no conflict of interest.

JE declares that he has no conflict of interest.

MS declares that he has no conflict of interest.

ES declares that she has no conflict of interest.

FF declares that he has no conflict of interest.

JS declares that she has no conflict of interest.

LH declares that he has no conflict of interest.

MR declares that he has no conflict of interest.

MWB declares that he has no conflict of interest. 
AT declares that she has no conflict of interest.

\section{Ethical approval}

All procedures performed in studies involving human participants were in accordance with the ethical standards of the institutional and/or national research committee and with the 1964 Helsinki declaration and its later amendments or comparable ethical standards.

This article does not contain any studies with animals performed by any of the authors.

$\underline{\text { Informed consent }}$

Informed consent was obtained from all individual participants included in the study.

\section{References}

1. WHO-UNEP. State of the Science of Endocrine Disrupting Chemicals 2013 [Available from: http://www.who.int/ceh/publications/endocrine/en/.

2. Johns LE, Ferguson KK, Soldin OP, Cantonwine DE, Rivera-Gonzalez LO, Del Toro LV, et al. Urinary phthalate metabolites in relation to maternal serum thyroid and sex hormone levels during pregnancy: a longitudinal analysis. Reproductive biology and endocrinology : RB\&E. 2015;13:4.

3. Kabir ER, Rahman MS, Rahman I. A review on endocrine disruptors and their possible impacts on human health. Environmental toxicology and pharmacology. 2015;40(1):241-58.

4. Casals-Casas C, Desvergne B. Endocrine disruptors: from endocrine to metabolic disruption. Annu Rev Physiol. 2011;73:135-62.

5. Casas M, Valvi D, Ballesteros-Gomez A, Gascon M, Fernandez MF, Garcia-Esteban R, et al. Exposure to Bisphenol A and Phthalates during Pregnancy and Ultrasound Measures of Fetal Growth in the INMA-Sabadell Cohort. Environ Health Perspect. 2016;124(4):521-8.

6. Huang Y, Li J, Garcia JM, Lin H, Wang Y, Yan P, et al. Phthalate levels in cord blood are associated with preterm delivery and fetal growth parameters in Chinese women. PloS one. 2014;9(2):e87430.

7. Xu C, Chen JA, Qiu Z, Zhao Q, Luo J, Yang L, et al. Ovotoxicity and PPAR-mediated aromatase downregulation in female Sprague-Dawley rats following combined oral exposure to benzo[a]pyrene and di-(2-ethylhexyl) phthalate. Toxicol Lett. 2010;199(3):323-32.

8. Ahmadian M, Suh JM, Hah N, Liddle C, Atkins AR, Downes M, et al. PPARgamma signaling and metabolism: the good, the bad and the future. Nat Med. 2013;19(5):557-66.

9. Woods MM, Lanphear BP, Braun JM, McCandless LC. Gestational exposure to endocrine disrupting chemicals in relation to infant birth weight: a Bayesian analysis of the HOME Study. Environmental health : a global access science source. 2017;16(1):115.

10. Maisonet M, Terrell ML, McGeehin MA, Christensen KY, Holmes A, Calafat AM, et al. Maternal concentrations of polyfluoroalkyl compounds during pregnancy and fetal and postnatal growth in 
British girls. Environmental health perspectives. 2012;120(10):1432-7.

11. Padmanabhan V, Siefert K, Ransom S, Johnson T, Pinkerton J, Anderson L, et al. Maternal bisphenolA levels at delivery: a looming problem? J Perinatol. 2008;28(4):258-63.

12. Cantonwine DE, Ferguson KK, Mukherjee B, McElrath TF, Meeker JD. Urinary Bisphenol A Levels during Pregnancy and Risk of Preterm Birth. Environmental health perspectives. 2015;123(9):895901.

13. Weinberger B, Vetrano AM, Archer FE, Marcella SW, Buckley B, Wartenberg D, et al. Effects of maternal exposure to phthalates and bisphenol A during pregnancy on gestational age. J Matern Fetal Neonatal Med. 2014;27(4):323-7.

14. Bayer CM, Bani MR, Schneider M, Dammer U, Raabe E, Haeberle L, et al. Assessment of breast volume changes during human pregnancy using a three-dimensional surface assessment technique in the prospective CGATE study. European Journal of Cancer Prevention. 2014;23(3):151-7.

15. Fejzo MS, Fasching PA, Schneider MO, Schwitulla J, Beckmann MW, Schwenke E, et al. Analysis of GDF15 and IGFBP7 in Hyperemesis Gravidarum Support Causality. Geburtshilfe und Frauenheilkunde. 2019;79(04):382-8.

16. Strakovsky RS, Schantz SL. Impacts of bisphenol A (BPA) and phthalate exposures on epigenetic outcomes in the human placenta. Environmental epigenetics. 2018;4(3):dvy022.

17. Brune B, Brune T. Epigenetik: Einfluss auf die fetale Entwicklung. Neonatologie Scan. 2017;06(01):5170.

18. Huang P-C, Kuo P-L, Guo Y-L, Liao P-C, Lee C-C. Associations between urinary phthalate monoesters and thyroid hormones in pregnant women. Human Reproduction. 2007;22(10):2715-22.

19. de Cock M, de Boer MR, Lamoree M, Legler J, van de Bor M. Prenatal exposure to endocrine disrupting chemicals in relation to thyroid hormone levels in infants - a Dutch prospective cohort study. Environmental health : a global access science source. 2014;13:106.

20. Mustieles V, Williams PL, Fernandez MF, Minguez-Alarcon L, Ford JB, Calafat AM, et al. Maternal and paternal preconception exposure to bisphenols and size at birth. Human reproduction (Oxford, England). 2018.

21. Wagner M, Oehlmann J. Endocrine disruptors in bottled mineral water: total estrogenic burden and migration from plastic bottles. Environmental Science and Pollution Research. 2009;16(3):278-86.

22. Wolff MS, Engel SM, Berkowitz GS, Ye X, Silva MJ, Zhu C, et al. Prenatal phenol and phthalate exposures and birth outcomes. Environmental health perspectives. 2008;116(8):1092-7.

23. Cantonwine D, Meeker JD, Hu H, Sanchez BN, Lamadrid-Figueroa H, Mercado-Garcia A, et al. Bisphenol a exposure in Mexico City and risk of prematurity: a pilot nested case control study. Environ Health. 2010;9:62.

24. Adibi JJ, Hauser R, Williams PL, Whyatt RM, Calafat AM, Nelson H, et al. Maternal urinary metabolites of Di-(2-Ethylhexyl) phthalate in relation to the timing of labor in a US multicenter pregnancy cohort study. Am J Epidemiol. 2009;169(8):1015-24. 
25. Albrizio S, Grumetto L, Mercogliano R, Mita DG. 8. Endocrine Disruptors: Hidden killers in our food. A mini review on some Italian products.

26. Gallo P, Di IMP, Esposito F, Fasano E, Scognamiglio G, Mita G, et al. Determination of BPA, BPB, BPF, BADGE and BFDGE in canned energy drinks by molecularly imprinted polymer cleaning up and UPLC with fluorescence detection. Food chemistry. 2017;220:406-12.

27. Fasano E, Esposito F, Scognamiglio G, Di Francesco F, Montuori P, Amodio CR, et al. Bisphenol A contamination in soft drinks as a risk for children's health in Italy. Food additives \& contaminants Part A, Chemistry, analysis, control, exposure \& risk assessment. 2015;32(7):1207.

\section{Figures}



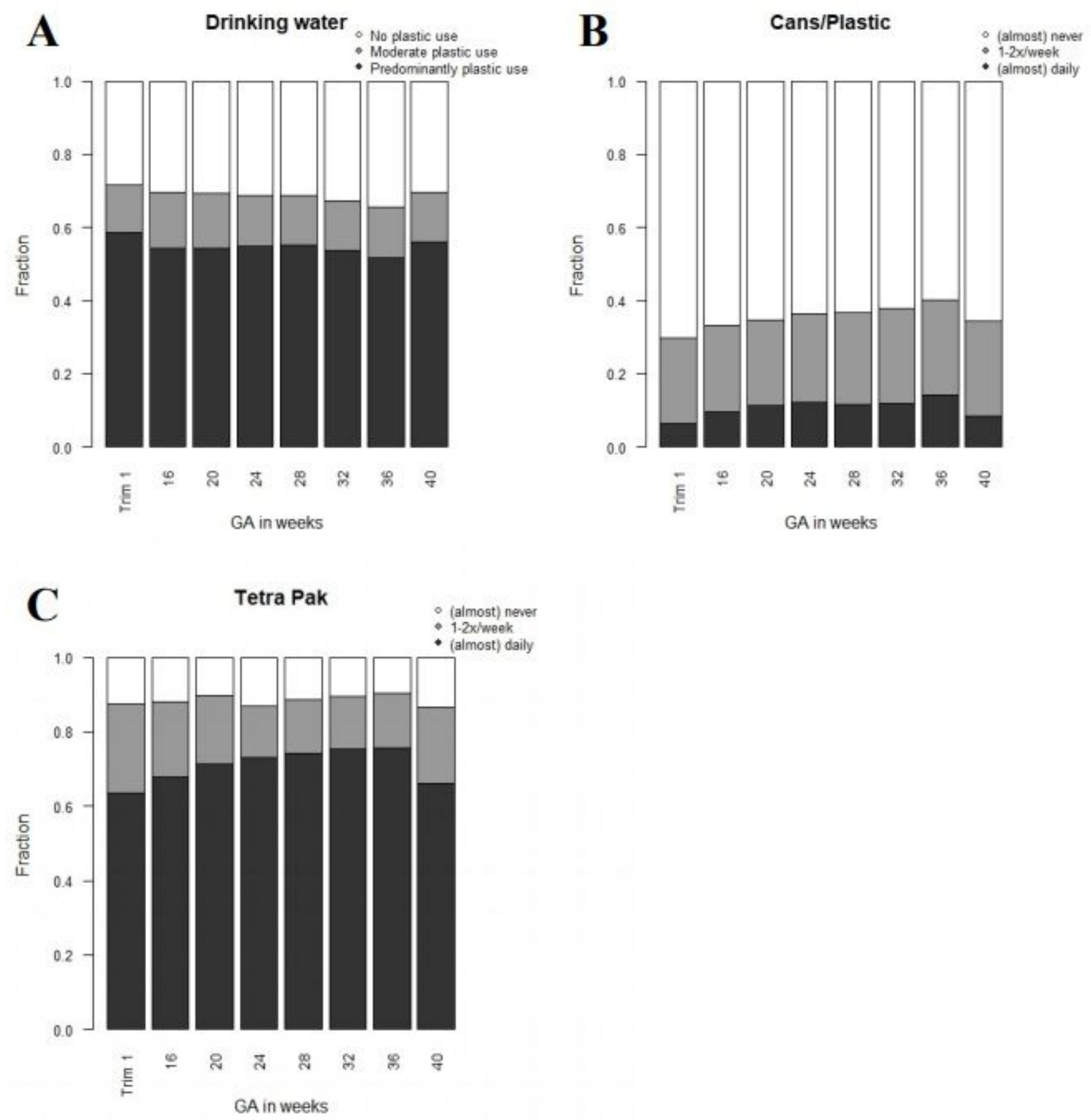

Figure 1

A-C Plastic packaging consumption habits for drinks and food within the CGATE cohort Barplots reveal consumption habits regarding plastic packaging modalities for drinks and food over all time points of the CGATE pregnancy diary questionnaire: A) Drinking water, B) Cans/Plastic, C) Tetra Pak (Trim 1 = First Trimester; GA = Gestational Age) 